\title{
Percutaneous management of a saphenous vein graft perforation using a covered stent and final coil embolization technique
}

\author{
Ben Glover, Paul Johnston, Mark Spence
}

Royal Victoria Hospital, Belfast, Great Britain

Submitted: 23 January 2010

Accepted: 28 January 2010

Arch Med Sci 2010; 6, 6: 991-992

DOI: 10.5114/aoms.2010.19317

Copyright $\odot 2010$ Termedia \& Banach

\author{
Corresponding author: \\ Ben Glover, MD \\ Royal Victoria Hospital \\ Grosvenor Road, Belfast, \\ BT12 6BA \\ Phone: +4402890240503 \\ E-mail: \\ ben.glover@hotmail.com
}

\begin{abstract}
Coronary artery perforation as a result of percutaneous coronary intervention is a rare complication which may result in cardiac tamponade, myocardial infarction and death. Perforation of a saphenous vein graft is unusual and generally requires surgical intervention. We describe a novel percutaneous approach that facilitated the successful management of a potentially catastrophic saphenous vein graft (SVG) perforation.
\end{abstract}

Key words: vein graft perforation

Coronary artery perforation as a result of percutaneous coronary intervention $(\mathrm{PCI})$ is a rare complication $(0.1 \%)$ [1] which may result in cardiac tamponade, myocardial infarction and death. The main predictors of coronary perforations are clinical (elderly, female gender), pharmacological (use of glycoprotein Ilb/Illa inhibitors), angiographic (small tortuous and calcified vessels) and procedural (stiff hydrophilic wires, artery to balloon ratio of $>1.2-1.3$, use of atherectomy device) $[1,2]$. We describe a novel approach that facilitated the successful management of a potentially catastrophic saphenous vein graft (SVG) perforation.

A 68-year-old female treated with CABG 5 years previously was referred for $\mathrm{PCl}$ after angiography demonstrated a significant SVG to the first obtuse marginal (OM) lesion. At PCI (right transradial access, 6 Fr Left Coronary Bypass (LCB) guide catheter (Cordis Corporation, New Jersey, USA)) the SVG was found to be occluded. A Pilot 50 wire (Abbott Laboratories, Illinois, USA) crossed the occlusion easily and the stenosis was pre-dilated with a $2.0 \mathrm{~mm}$ and a $4.0 \mathrm{~mm}$ balloon. Contrast injection via an Export catheter demonstrated intraluminal wire position and a good sized distal OM. A $4.5 \times 24$ Liberte stent (Boston Scientific, Natick, USA) was deployed at 17 atmospheres resulting in a class 3 perforation (Figure 1 . A), tachycardia and hypotension [2].

The stent balloon was immediately positioned within the stent and inflated to control the perforation. Intravenous protamine was administered and a transthoracic echocardiogram showed a posterior pericardial effusion with compression of the posterior left atrial wall in a position almost impossible to treat with percutaneous pericardiocentesis (Figure 1. B). With the inflated balloon controlling the perforation a second 8 French LCB guide catheter was introduced from the femoral artery and positioned at 


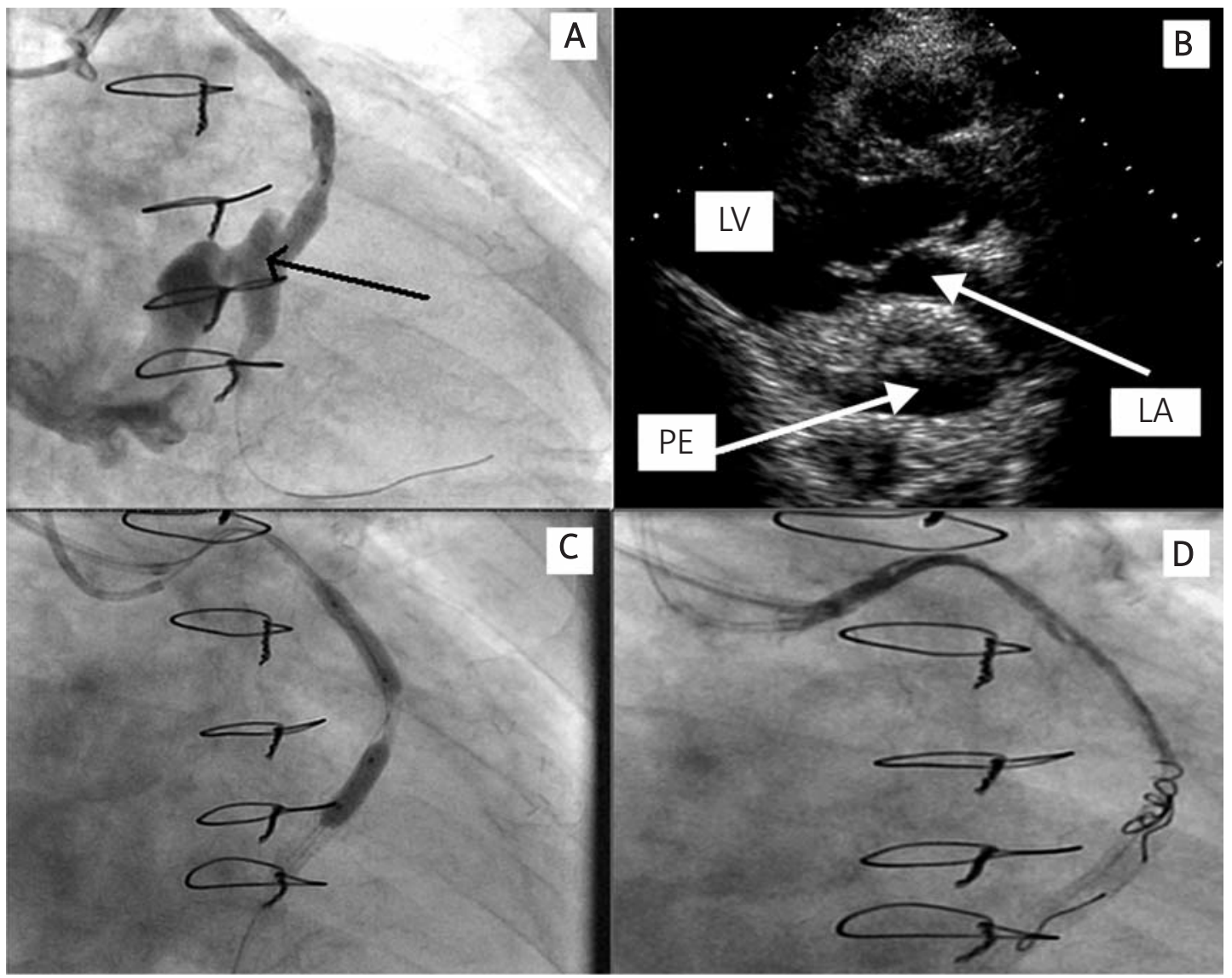

Figure 1. A - Class 3 SVG perforation following stent deployment. B - posterior pericardial effusion with compression of left atrium. C - positioning of covered stent over site of perforation using 2 guides and a proximal balloon. $D$ - use of coils to achieve complete occlusion of SVG perforation

$P E$ - pericardial effusion, $L A$ - left atrium, LV - left ventricle, arrow indicates the site of the perforation

the ostium of the SVG alongside the original guide, which was partially backed out of the SVG ostium. A BMW wire (Guidant Corporation, Temecula, California, USA) was passed through to the distal vessel with a brief deflation and immediate re-inflation of the balloon controlling the perforation. A $4.0 \times 15 \mathrm{~mm}$ balloon was then advanced along this second wire and positioned and inflated in the graft proximal to the first balloon. With the second balloon in place proximally, brief deflation and re-inflation allowed controlled removal of the balloon at the perforation site and deployment of a $4.5 \times 19 \mathrm{~mm}$ covered Jostent (Abbott Laboratories, Illinois, USA) at the perforation site with minimal further flow into the pericardial space (Figure 1. C). Using the same technique a $4.0 \times 12 \mathrm{~mm}$ Jostent was deployed, overlapping with the initial covered stent. A small contrast leak persisted and coil embolization of the SVG with 4 Cook MicroNester ${ }^{\circledR}$ Embolization Microcoils ${ }^{\text {TM }}$ (Cook Medical, Bloomington, USA) was performed via a microcatheter (2.4 F Progreat, Terumo [Leuven, Belgium]), achieving complete occlusion (Figure 1. D). The pericardial collection resolved over 7 days. The patient remains well at six months and is currently angina free.

This case demonstrates how the novel use of a proximal balloon introduced via a second guide allowed controlled removal of the balloon sealing the perforation and delivery of covered stents and coils without further catastrophic bleeding into the inaccessible posterior pericardial space.

\section{References}

1. Ellis SG, Ajluni S, Arnold AZ, et al. Increased coronary perforation in the new device era. Incidence, classification, management, and outcome. Circulation 1994; 90: 2725-30.

2. Muller O, Windecker S, Cuisset T, et al. Management of two major complications in the cardiac catheterisation laboratory: the no-reflow phenomenon and coronary perforations. Eurolnterv 2008; 4: 181-92. 